\title{
TEATRO E PERFORMANCE NA EDUCAÇÃO INFANTIL: [COR]POSSIBILIDADES PARA UMA EDUCAÇÃO SENSÍVEL
}

\author{
Rafael Koehler ${ }^{l}$ \\ Michelle Bocchi Gonçalves ${ }^{2}$ \\ Jean Carlos Gonçalves ${ }^{3}$
}

INTRODUÇÃO

O novo século já é conhecido como o século da informação. Este acesso constante à informação se tornou possível, especialmente, através da difusão da internet. Ao mesmo tempo em que existem inúmeras vantagens e benfeitorias nessa relação com o mundo virtual, percebe-se uma mudança social nas interações humanas, influenciadas diretamente por essa nova configuração de relação que a internet e o novo século trouxeram. Estamos presenciando uma sociedade que caminha para a perda da sensibilidade no seu dia-a-dia, e isso tem consequências diretas no educando e na escola atual. Uma das propostas que tentam repensar a educação, levando em consideração a sociedade contemporânea é a da Educação Sensível (ARENHARDT et al, 2006; PILLOTTO, 2007; VANI, 2013; entre outros).

\footnotetext{
1 Ator e professor de teatro. Licenciado e Bacharel em Teatro pela Universidade Regional de Blumenau (FURB) e Mestrando em Educação: Teoria e Prática de Ensino na Universidade Federal do Paraná (PPGE: TPEn/UFPR). koehler.r@gmail.com

2 Doutora em Educação pela Universidade Federal do Paraná (PPGE/UFPR). Professora Adjunta do curso de Licenciatura em Educação do Campo (LECAMPO/UFPR) e do Programa de Pós-Graduação em Educação: Teoria e Prática de Ensino (PPGE: TPEn/UFPR), orientando pesquisas na área dos Estudos da Performance na Educação e Estudos Discursivos na Educação (Análise do Discurso de linha francesa). michellebocchi@gmail.com

3 é Doutor em Educação pela Universidade Federal do Paraná (PPGE/UFPR), com estágio de pós-doutorado no Programa de Estudos Pós-Graduados em Linguística Aplicada e Estudos da Linguagem da Pontifícia Universidade Católica de São Paulo (LAEL/PUC-SP). Professor Adjunto do curso de Produção Cênica (TPC/UFPR) e dos Programas de PósGraduação em Educação (PPGE/UFPR) e Educação: Teoria e Prática de Ensino (PPGE: TPEn/UFPR), orientando pesquisas na área de Teatro-Educação e Estudos Discursivos na Educação (Análise Dialógica do Discurso). jeancarllosgoncalves@gmail.com
} 
A sociedade está em constante mudança, cultural e tecnológica, e a cada dia se torna mais acelerada e agitada. Em razão disso, os jovens e crianças têm grandes dificuldades de se posicionarem de maneira que possam se disponibilizar a ouvir o que o outro tem a dizer. O que percebemos, hoje, é que crianças e adolescentes tem crescido focadas no individualismo, com um aumento das dependências da tecnologia, e um grande enfraquecimento dos vínculos humanos (CANIATO; NASCIMENTO, 2010). Esta situação se agrava ao estar combinada com a troca do contato físico pelo contato virtual, e isso resulta em um deixar de olhar para o colega, deixar de ouvir, de perceber. Já está evidente o quanto as relações familiares e sociais mudaram nos últimos anos, aumentando uma carência de momentos de diálogo presencial, substituindo-os gradativamente por meios de mediação eletrônicos (OLIVEIRA, 2009).

Todo esse contexto social percebido nessas duas primeiras décadas do novo século reflete diretamente no ambiente escolar. Os estudantes chegam, desde pequenos, imersos nesse mundo de incertezas, de emoções descartáveis, do efêmero, do egocentrismo. O resultado se vê diariamente dentro das escolas: desde dificuldade de relação, de ouvir, aceitar a opinião e proposta do outro, até atitudes de desrespeito e desconsideração pelo dizer do outro. Tudo isso influi diretamente na relação entre professor/educando, educando/educando e demais membros da comunidade escolar.

\footnotetext{
Muitos são os fatores para tal situação; os meios de comunicação que vendem muitas vezes uma imagem inadequada da realidade; o consumo exacerbado, que nos leva a consumir cada vez mais e em muitos casos na tentativa de suprir afetos, solidão, dúvidas e tantos outros sentimentos. Mais do que isso e para, além disso, o professor reproduz em suas práxis educativas o que absorveu e absorve desses meios e da cultura massificada que impregna nossas mentes e nossas almas. A grande questão então é: o que podemos fazer para não perdermos de vista a sensibilidade? (PILLOTTO, 2007a, p.119)
}

Essa contextualização das relações da sociedade contemporânea é fundamental para compreendermos o lugar de onde partimos, o quanto estas dimensões de individualismo, egocentrismo, de tecnologia utilizada de uma maneira equivocada, e da perda da sensibilidade entre os sujeitos da interação, interferem cada vez mais no processo de ensino-aprendizagem, e o porquê é proposto se pensar uma educação sensível, tendo o teatro e a performance como fortes aliados nesse processo.

A aprendizagem acontece na interioridade de cada ser; ensinar e aprender são momentos que necessitam do contato com o outro, de uma troca entre mais de um indivíduo. Troca esta que se dá não apenas tecnicamente, mas emocionalmente, afetivamente e eticamente. 
Infelizmente, o modelo de escola atual predominante no Brasil tem reforçado ainda mais os problemas inerentes às relações humanas da sociedade contemporânea. Com práticas educativas fragmentadas, tanto nos espaços físicos quanto na sistematização de conceitos/conteúdos que revelam, a partir de práticas pouco eficientes, suas fragilidades, acaba-se por negligenciar as emoções/sensibilidades dos educandos e educadores, estimulando, muitas vezes, toda essa inversão de valores e sentimentos que fortalece o individualismo tão presente na sociedade atual.

Métodos de ensino voltados ao pensamento linear e fragmentado, que se subdividem em disciplinas dentro de uma estrutura que dificulta a troca entre professores e estudantes, ainda encontram na escola um lugar para existir e reverberar. $\mathrm{O}$ trabalho ideia de que para compreender o mundo o estudante necessita apenas construir um pensamento racional a partir de números e letras, e que apenas com isso ele conseguirá compreender a sociedade, não pode corresponder às urgências e demandas do sujeito do século XXI que, cada vez mais, se desencontra e se perde nas efervescências virtuais que surgem a cada minuto em velocidade nunca antes vista.

No século XXI, ainda, “a educação pela via do sensível é por vezes considerada menos importante que os aspectos cognitivos, que indicam na concepção de algumas escolas sucesso futuro" (PILLOTTO, 2007a, p.114). Para o modelo de escola predominante no Brasil atual o 'sucesso futuro' está ligado apenas à construção intelectual de conhecimento, ignorando que a complexidade humana vai muito além do racional. Se quisermos pensar em uma sociedade mais altruísta, não podemos negligenciar a construção de conhecimento a partir da sensibilidade.

É aí que o teatro e a performance se apresentam como [cor]possibilidades para se pensar uma educação sensível já na pequena infância, ou seja, ao entrar em contato com práticas corporais em caráter experimental, a criança pode vislumbrar outras sensações e ser instigada a processos criativos que se desencadeiam por outras vias que não aquelas mais comuns. A ideia de [cor]possibilidades pode ser concebida então no entre-lugar do corpo e de seus potenciais, atravessando tanto as práticas teatrais quanto a performance das crianças quando estas se colocam em experimentação de si e de seus corpos a partir da mediação do professor.

A próxima seção do artigo se debruça sobre a noção de educação sensível, abordando aspectos fundamentais para a compreensão de seu funcionamento e aplicação teórico-prática no campo da educação. 


\title{
EDUCAÇÃO SENSÍVEL
}

A proposta de uma educação sensível nasce como elemento imprescindível na apropriação e na internalização dos conhecimentos através da sensibilidade. Tem como base o compartilhamento de vivências, possibilitando ao educando se abrir ao outro, percebendo e desenvolvendo a sensibilidade de ouvir, de ver e de falar, de compreender a si mesmo e ao outro, de modificar e ser modificado pelas ações e pelo discurso alheio (VANI, 2013).

Pensando nisso, podemos relacionar um processo educacional sensível com o dialogismo, conceito central dos estudos de Bakhtin e o Círculo ${ }^{4}$ :

\begin{abstract}
A orientação dialógica é naturalmente um fenômeno próprio a todo discurso. Trata-se da orientação natural de qualquer discurso vivo. Em todos os seus caminhos até o objeto, em todas as direções, o discurso se encontra com o discurso de outrem e não pode deixar de participar, com ele, de uma interação viva e tensa. Apenas o Adão mítico que chegou com a primeira palavra num mundo virgem, ainda não desacreditado, somente este Adão podia realmente evitar por completo esta mútua orientação dialógica do discurso alheio para o objeto. Para o discurso humano, concreto e histórico, isso não é possível: só em certa medida e convencionalmente é que pode dela se afastar. (BAKHTIN, 1998, p.88)
\end{abstract}

A educação é, por excelência, dialógica, e tem como objetivo resultar na compreensão e transformação da realidade pelo estudante.

A perspectiva dialógica é, por natureza, dialógica e está, portanto, mais do que se imagina, instaurada como teoria que pensa a escola, a universidade, o professor, o aluno, as metodologias, as didáticas, as organizações pedagógicas, os planos de ensino, etc. O que é a educação senão um jogo de relações humanas? O que é o objeto de pesquisa em educação senão o próprio homem, o próprio sujeito em relação com o outro? O que é fazer educação senão dialogar com o outro e nesse processo ensinar e aprender? (GONÇALVES, 2016, p.221)

Ao defender uma educação sensível se discute intrinsecamente a relação dialógica educacional. Pillotto (2007a) destaca cinco aspectos que contribuem para uma educação pela via do

\footnotetext{
${ }^{4}$ Expressão utilizada para fazer referência ao grupo de intelectuais russos que teve uma intensa produção sobre a linguagem no início do Séc. XX em uma Rússia czarista e em revolução. Entre seus membros, os mais conhecidos no Brasil são Mikhail Bakhtin, Pável Medviedev e Valentin Volochinov. Os estudos bakhtinianos tem oferecido importantes contribuições ao campo da educação, como discute Gonçalves (2012; 2016). Esta corrente tem sido denominada também de perspectiva dialógica, estudos bakhtinianos, pensamento bakhtiniano e Análise Dialógica do Discurso.
} 
sensível: intuição, percepção, emoção, criação e sensibilidade - que serão apresentadas a seguir a partir dos conceitos da autora - e todas só são possíveis a partir de uma relação dialógica verdadeira entre elas, na compreensão de que "O dialogismo são as relações de sentido que se estabelecem entre dois enunciados" (FIORIN, 2016, p.22). Se pensarmos, desse modo, na relação dialógica educacional, são as posições enunciativas entre educadores e educandos que constroem os sentidos e os conhecimentos nesse processo de inter-relação constante.

No processo de educação atual, como já citado, os professores são direcionados, mesmo que indiretamente, a ressaltar apenas a razão. Prática esta que se materializa nas notas, no preenchimento dos diários de classe, nos relatórios, nas planilhas e planos de ensino, etc. Mas para auxiliar na formação de um estudante sensível é preciso ampliar essa noção de escolarização dando uma importância para a intuição da mesma maneira que se dá para o intelecto. No ser humano a razão e a intuição estão interligadas.

O conhecimento construído é mais do que intelectual, é também intuitivo, é um conhecimento global das coisas. Internalizamos vários aspectos de um fenômeno, interpretando-os a partir da percepção que temos do que vemos, de onde estamos e da história que construímos. Essa seleção passa pelo limiar do racional e da sensível. Assim, a história que construímos a partir dos fragmentos que temos - afetos, emoções, associações - integra um conjunto de elementos que se relacionam formando uma rede subjetiva de significados. Esse processo é sempre um novo conhecimento, sobre nós mesmos e sobre os outros. (PILLOTTO, 2007a, p.117)

Em sala de aula essa rede subjetiva de significados auxilia nas relações afetivas entre o professor e os educandos, pois o professor ao intuir, tanto sobre ele mesmo, quanto sobre os estudantes, tanto sobre o contexto interno, quanto externo da escola, amplia o seu entendimento sobre os acontecimentos em sala e percebe com maior facilidade como ocorrem os processos de ensinoaprendizagem e as variações desse processo em cada turma, auxiliando assim a produção de sentidos dos educandos.

Porém, para conhecer melhor um tema e sua significação e intuir sobre, é necessário aguçar a percepção, que tem como base a capacidade do ser humano sentir e compreender tanto a si mesmo quanto aos outros, tudo ao mesmo tempo, de forma dinâmica.

A percepção é um elemento sutil, mas é possível perceber a criança pelo que ela expõe a partir da visibilidade do seu corpo, dos seus gestos e dos sons que profere. 
Crianças! Universos múltiplos, diversos modos de ser e viver a infância! As teorias, os fundamentos pedagógicos podem oferecer ao educador um roteiro, uma pista para a aproximação das crianças, mas nada substituirá o encontro com esses universos, se quisermos revelar as crianças na sua plenitude. Para uma prática educativa que pretenda respeitar o tempo da infância, é essencial o olhar a criança, os movimentos dos grupos: vendo, ouvindo e acolhendo suas perguntas, seus achados, suas descobertas - seja por meio do choro, do balbucio, do gesto, do movimento ou da palavra. (OSTETTO, 2007, p.35)

O estudante, a criança, também tem sua percepção sobre o professor e a aula, e é importante ressaltar que tudo que acontece dentro e fora da escola interfere no que o educando deseja perceber da aula, seus interesses, necessidades, dúvidas, problemas, etc. E cabe ao educador estar atento aos sinais que os estudantes dão sobre o que e como percebem a aula. "O mundo interior é formado a partir da heterogeneidade dialógica das vozes sociais (...). O sujeito é integralmente social e integralmente singular" (FIORIN, 2016, p.64), ou seja, o estudante constrói o seu pensamento, e seus enunciados, a partir da percepção que ele tem do mundo externo e da contraposição entre a realidade/vozes sociais e a sua consciência, seu mundo interno, tornando o sujeito um ser único e singular.

A subjetividade é constituída pelo conjunto de relações sociais de que participa o sujeito. Por isso, em Bakhtin, o sujeito não é assujeitado, ou seja, submisso às estruturas sociais, nem é uma subjetividade autônoma em relação à sociedade. O princípio do agir é que o sujeito atua em relação aos outros; o indivíduo constitui-se em relação ao outro (FIORIN, 2016, p.60)

Em sala de aula é necessário trabalhar a percepção, pois, "a única certeza é que no que se percebe, se interpreta; no que se apreende, se compreende" (PILLOTTO, 2007a, p.120), ou seja, para compreender é necessário perceber. Isso não ocorre somente de forma intelectual, mas também de forma sensível, intuitiva, afinal todo aprendizado deixa marcas em nossa experiência.

Aquilo que realmente nos atravessa, nos toca, é o que aprendemos, e isso acontece porque percebemos e relacionamos com nossa vida, e são essas experiências que podem mudar a nossa forma de ver o mundo e de nos percebermos como seres humanos. Concordamos com Larrosa, para quem "A experiência é o que nos passa, o que nos acontece, o que nos toca. (...) A cada dia se passam muitas coisas, porém, ao mesmo tempo, quase nada nos acontece” (LARROSA, 2002, p.21).

Dar voz e lugar à experiência constitui-se, hoje, como um clamor necessário para que o afeto e a sensibilidade se encontrem nos espaços educacionais e possam revelar, assim, as consequências 
desse encontro, especialmente quando estão em jogo os primeiros passos da criança em direção aos outros e ao conhecimento de suas próprias emoções e reações.

Não é mesmo novidade dizermos que é pelas diferentes experiências com/no mundo sensível que a criança vai se apropriando de formas mais complexas de ver e ler esse mesmo mundo sentido. Tampouco causaria surpresa dizermos que, no processo de conhecer, há um percurso que passa pela curiosidade, pelo mistério e pela magia do mundo, alcançados pela experiência. Então, afirmo a obviedade para fazê-la límpida: conhecer, nesse sentido, é viver uma experiência. E onde está o conhecimento? No mundo! É preciso reafirmar, pois às vezes tenho a impressão de que esquecemos: ele não é escolar, tampouco só científico; é estético, poético, é muito mais. (OSTETTO, 2007, p.35-36)

É necessário compreender o educando e suas experiências com o maior número de detalhes possível e estar aberto para que o estudante perceba o professor igualmente em detalhes. Assim será possível um intuir sobre o outro e juntos intuírem sobre o processo de ensino-aprendizagem e sobre o tema tratado na aula.

Para que os educadores possam desenvolver um trabalho que atenda as diversas realidades que a eles chegam, é necessário que sejam sensíveis o suficiente para sentir as necessidades de seus alunos educando-os para que sejam também sensíveis de maneira que cresçam e possam atuar na sociedade de forma crítica - criativa - conscientes de suas atitudes e possibilidades. E que, se sintam sujeitos atuantes na transformação do meio ao qual estão vinculados e não meros tarefeiros ou seguidores de normas. (ARENHARDT ET AL, 2006, p.03)

Com a percepção e a intuição aguçadas, a comunicação entre professor e estudante se torna mais real e é possível chegar a lugares pouco acessados dentro da educação atual como, por exemplo, os lugares do teatro e da performance como formas de educação sensível atravessadas pela relação intrínseca com o corpo.

A comunicação acontece também pela via das emoções. É possível intuir sobre o educando através da percepção das emoções que transbordam o seu corpo, seja pela maneira de olhar, de entonar uma fala, de gesticular, ou até mesmo na ausência desses e outros sinais subjetivos da emoção.

A percepção emocional é indispensável para a comunicação entre professor-estudante, para a compreensão e a construção de conhecimento. É importante desenvolver, na prática pedagógica, ações que envolvam o outro, que auxiliem os educandos a aprenderem a lidar com suas próprias 
emoções e as emoções dos outros, para que quando envoltos no processo de aprendizagem consigam ter um olhar sensível que, ao mesmo tempo, se abra para possibilidades de uma relação dialógica educacional e que possa alcançar o amadurecimento emocional, no intuito de que os enfrentamentos de opiniões não desestimulem os participantes da interação no ambiente escolar mas, pelo contrário, que as divergências, perguntas e respostas os instiguem a gerar novas interlocuções com o conhecimento..

Pergunta e resposta não são relações (categorias) lógicas; não podem caber em uma só consciência (uma e fechada em si mesma); toda resposta gera uma nova pergunta. Se a resposta não gera uma nova pergunta, separa-se do diálogo e entra no conhecimento sistêmico, no fundo impessoal. (BAKHTIN, 2003, p.408)

É a um conhecimento sistêmico, impregnado na educação brasileira, há séculos, que a proposta da educação sensível se contrapõe. Necessitamos de estudantes e educadores que com intuição, percepção e controle emocional que consigam, juntos, em completa dialogia, tomar decisões em sala de aula que possibilitem novas interfaces entre educação e processos de criação no contexto escolar.

Para criar é necessário estar aberto, permanentemente, às emoções e sensações. A criação, e o seu processo, estão relacionados à intuição, à sensibilidade, e são inerentes ao ser humano. Em sala de aula, exercitar o processo criativo com os educandos é abrir espaços para o novo, pois a criação é responsável por ativar o corpo, a mente e as emoções, envolvendo diretamente aspectos teóricos, práticos, cognitivos e sensíveis.

Compreender o estudante (no caso desta investigação, a criança) para além do cognitivo é fundamental para uma convivência e uma aprendizagem, de fato, significativas. A sensibilidade possibilita ao ser humano perceber-se e, a partir desta percepção, transformar a sua própria realidade. A maneira que compreendemos a realidade está diretamente ligada ao quão sensível somos aos acontecimentos dela. Pensando nisso é que a educação sensível propõe uma sala de aula com professores e estudantes que tenham sensibilidade pela vida e pelo ato de existir.

Percebe-se que, ao estabelecer boas relações com os outros, estas refletirão em melhores condutas sociais, ou seja, quando estabelecemos atitudes de respeito e aceitação por nós mesmos e pelo próximo, efetivaremos os deveres que nos competem enquanto cidadãos comprometidos com as ações mediante uma sociedade mais humana, que se respeita e compreende o outro nas suas peculiaridades. (VANI, 2013, p.9) 
A construção de conhecimento acontece tanto dentro quanto fora do ambiente escolar, numa relação constante entre racionalidade e sensibilidade. Estes são elementos fundamentais que devem ser trabalhados para que possamos ver, ao menos, micro-mudanças no sistema educacional. É fundamental que se pense na sensibilidade do estudante e em maneiras de exercitá-la, seja através das artes ou de outras fontes que possibilitem ao educando se perceber e se modificar, tornando-se cada vez mais sensível ao outro.

$\mathrm{O}$ ato de educar acontece em constante interação com o outro - seja professor/educando ou educando/educando ou ainda professor/professor - e nessa ação recíproca de troca de vivências e experiências é que se possibilitam olhares afetivos que poderão resultar em uma sociedade mais altruísta.

\section{DO TEATRO E DA PERFORMANCE NA EDUCAÇÃO INFANTIL}

Quando se discute uma educação que paute também o desenvolvimento do sensível no estudante, não apenas da razão, do intelecto, em que é disseminada a ideia de que basta construir número e letras para conseguir decodificar o mundo, temos a tendência de focar apenas no Ensino Fundamental - Anos Iniciais e Finais, e esquecemo-nos da Educação Infantil, uma das fases da Educação Básica mais importantes para se desenvolver o sensível. É necessário questionar que tipo de educação devemos pensar e realizar com crianças até cinco anos.

\footnotetext{
O que realmente importa às crianças nessa fase? Aprender a decodificar ou brincar aprendendo? Seguir rituais cotidianos, previsíveis e repetitivos ou esperar curiosamente pelo inesperado? Desenvolver atividades mecânicas, a fim de melhorar sua coordenação motora, disciplina e outros tantos aspectos ou estar envolvida com o lúdico e com a possibilidade de sonhar o “isonhado"? (PILLOTTO, 2007b, p.25)
}

Na Educação Infantil, em especial, não podemos, jamais, nos pautar apenas em uma educação racional. Precisamos compreender que o processo de construção de conhecimento da criança se dá pela via do lúdico, do jogo e das relações com o brincar. A arte e uma compreensão do corpo como performance são caminhos que mais possibilitam trabalhar a partir do e para o sensível, afinal, como linguagem a arte é expressão, comunicação, produção de sentidos; e como performance, o corpo se manifesta e discursa. Teatro e performance podem ser compreendidos, assim, como possibilidades 
de pensar a educação a partir da intuição, percepção, emoção, criação, sensibilidade, aspectos base para uma educação pela via do sensível.

O grande desafio da Educação Infantil é construir um currículo no qual o ensino de Arte se contraponha a currículos estruturados a partir de sequencias de atividades, de festividades com base no calendário cultural brasileiro ou local, ou, até, currículo centrado em rotinas padronizadas que mais visam o controle e ao disciplinamento dos corpos, desconsiderando as necessidades e potencialidades das crianças. (PEREIRA, 2016, p.38)

Nesta investigação, teatro e performance são compreendidos como elementos interdependentes ao se trabalhar com processos de criação no campo da educação. Enquanto a noção de teatro conecta-se ao campo da linguagem cênica, a performance é abordada como campo expandido que extrapola o campo da arte, a partir dos Performance Studies, de Schechner (2003, 2006, 2010) e Taylor (2013). Não é objetivo do presente artigo, discutir tais concepções separadamente, de modo isolado uma da outra. Antes, defendemos, aqui, um olhar para o teatro e/ou para a performance como possibilidades para se pensar uma educação sensível ${ }^{5}$. O termo [cor]possibilidades é, desse modo, o ponto de convergência entre teatro e performance já que é, mais do que tudo, pelas vias do corpo e do afeto que uma educação sensível pode se concretizar.

Parte das crianças tem contato com a arte, por exemplo, apenas nos espaços educacionais, por isso é importante que as relações entre arte e performance se expandam na educação, e possam ampliar a experiência cultural da criança, fornecendo-lhe base sólida para que venha a desenvolver sua capacidade criadora. A Educação Infantil é o período ideal para a construção dessa base, tanto pela idade das crianças, quanto pela não existência de uma grade curricular fechada, pois possibilita auxiliar desde o começo da educação a constituição de um sujeito criador envolto num universo poético e sensível. "É fundamental que o trabalho dos profissionais da Educação Infantil, que é a primeira etapa da Educação Básica, considere a criança pequena como sujeito que constrói, expressa e comunica significados e sentidos" (PEREIRA, 2016, p.37).

O trabalho com o teatro e a performance na Educação Infantil é uma das reais possibilidades para auxiliar nessa construção. Para que as brincadeiras, experimentações e jogos aconteçam, é necessário que a criança crie de maneira imaginativa, onde cada detalhe mínimo ganha relevância e

\footnotetext{
${ }^{5}$ Ver o artigo Teatro ou performance? Quando os discursos atravessam os procedimentos de Ludmila Castanheira, 2017)
} 
a sua cognição esteja em permanente desconstrução e reconstrução, a partir das quais percepção, intuição, emoção, imaginação e sensibilidade confluam para essa criação.

Um dos pontos que alicerçam o teatro e a performance - e os processos de criação como um todo - no contexto da Educação Infantil, é a educação do olhar que expande as leituras e percepções de mundo, que possibilite a criança não apenas olhar, mas ver.

Ao ver, estamos entrelaçando informações do contexto sociocultural, onde a situação ocorreu, e informações do leitor, seus conhecimentos, suas inferências, sua imaginação. É preciso, no entanto, ter claro que esta leitura, esta percepção, esta compreensão, esta atribuição de significados vai ser feita por um sujeito que tem uma determinada história de vida, em que objetividade e subjetividade organizam, de modo singular, sua forma de apreensão e de apropriação do mundo. (PILLAR, 2008 p.74)

O contato com o teatro e com a performance amplia, assim, as percepções e concepções de mundo das crianças. Durante os jogos e experimentações as crianças se apropriam de elementos do seu entorno, e o fazem com base em seus próprios referenciais, que podem ser ampliados ao estar em relação com os referenciais do outro.

O jogo dramático é uma parte vital da vida jovem. Não é uma atividade de ócio, mas antes a maneira da criança pensar, comprovar, relaxar, trabalhar, lembrar, ousar, experimentar, criar e absorver. O jogo é na verdade a vida. A melhor brincadeira teatral infantil só tem lugar onde oportunidade e encorajamento lhe são conscientemente oferecidos por uma mente adulta. Isto é um processo de "nutrição" e não é o mesmo que interferência. É preciso construir a confiança por meio da amizade e criar a atmosfera propícia por meio de consideração e empatia. (SLADE, 1978, p.18)

A educação acontece na relação de um com o outro, do professor-educando, educandoeducando, da relação entre a mente adulta e a infantil, e os procedimentos teatrais e/ou performativos, como tem o princípio da coletividade, contribuem muito com esse processo de relacionar-se com o outro. A educação, o teatro e a performance são naturalmente dialógicos. O dialogismo, de acordo com o pensamento bakhtiniano, "faz que um enunciado se constitua sempre em relação ao outro" (FIORIN, 2016, p.90), sendo assim o dialogismo é a relação de sentido que se estabelece entre dois enunciados; e o enunciado tem relação direta com a realidade e com o sujeito. 
Não existe um consenso sobre o conceito de enunciado dentro dos estudos da linguagem, o que existe é uma grande polissemia nas definições e empregos do mesmo. "Grosso modo, é possível dizer que enunciado, em certas teorias, equivale a frase ou sequências frasais" (BRAIT; MELO, 2016, p.63, grifos das autoras).

Quando pensamos em Educação Infantil precisamos levar em consideração que as muitas vozes que vem do enunciado infantil não são apenas vozes da oralidade. Em diversas ocasiões são vozes corporais, físicas e emocionais que se expressam através da corporeidade infantil. Essas vozes unidas produzem sentidos através do diálogo com o professor ou com outros educandos. O trabalho com teatro e performance, nessa fase da Educação Básica é essencial para dar voz às crianças e coloca-las em relação direta com as vozes dos demais, iniciando assim uma relação verdadeira do eu com o outro, do saber ouvir e saber falar, do ser sensível ao outro e ser sensível para se compreender em processo de formação humana.

Os diferentes experimentos corporais na Educação Infantil dão às crianças a [cor]possibilidade de novas experiências. Ao experimentar personagens ${ }^{6}$, ao se colocar no lugar do outro, através dos jogos/brincadeiras/cantigas, as crianças produzem sentidos, criam e recriam a partir das realidades, através dos diálogos corporais (em uma faixa etária menor), e diálogos corporais e orais (em uma faixa etária maior), ressignificando e reconstruindo situações, dando possibilidade de compreenderem o mundo a partir de uma relação mais sensível.

As relações humanas, cerceadas pela coletividade, e o dialogismo estão intrínsecas no trabalho teatral-performativo, por isso é fundamental pensar tais [cor]possibilidades na Educação Infantil como necessárias para uma educação voltada aos sentidos, ao afeto, ao diálogo. Ao mesmo tempo em que colaboram para o desenvolvimento da comunicação entre os estudantes e professores, a urgência de se pensar o teatro e a performance na Educação Infantil está conectada ao favorecimento da produção coletiva, da produção e circulação de sentidos, do desenvolvimento da intuição, percepção, emoção e criação, o que nos permite defendê-las como áreas que, embora ainda pouco consideradas quando se fala de Educação Infantil, possuem grande possibilidade de contribuir para o desenvolvimento da sensibilidade da criança pequena.

\footnotetext{
${ }^{6}$ Personagem, compreendida nesta pesquisa, em uma perspectiva bastante ampla que, assim como a performance, extrapola o campo do teatral. Ver a obra A Personagem, de Beth Brait (2017).
} 


\section{CONSTRUINDO [COR]POSSIBILIDADES PARA UMA EDUCAÇÃO SENSÍVEL}

A educação sensível compreende o educando em toda a sua complexidade e leva em consideração tanto a razão quanto a sensibilidade no processo de aprendizagem, sendo o teatro e a performance possibilidades experimentais absolutamente relevantes quando se fala no desenvolvimento de aspectos do sensível no estudante/na criança.

As crianças e adolescentes contemporâneas nasceram em um mundo tecnológico e com menos interação social, o que resulta em educandos menos sensíveis ao outro e com maior dificuldade de expressar seus sentimentos. Tudo isto está em consonância com o sistema de ensino predominante no Brasil, onde os métodos de ensino são fragmentados e lineares, não levando em consideração o emocional do estudante, e resultando em um agravamento da situação social atual.

A escola, normalmente, é o local onde a criança começa a ter um contato real de convivência em sociedade, com toda a sua diversidade de pensamentos, etnias, sexualidade, gêneros, etc. Por este motivo é imprescindível, se quisermos uma sociedade mais humana, buscar meios de acesso ao trabalho com a sensibilidade e com o desenvolvimento da empatia, já que uma das tarefas mais difíceis do professor, atualmente, é fazer com que os educandos consigam conviver harmonicamente com toda essa diversidade social.

O conhecimento construído dentro da escola não é apenas intelectual, ele é também sensível. Ao compreender que o conhecimento se constrói através da intuição e da percepção, que para criar é necessário entender suas emoções, o educando se torna um ser com maior sensibilidade, consegue perceber aspectos emocionais dos colegas e professores, intuir sobre como agir para auxiliar na aprendizagem e nas relações diárias dentro da escola, e consequentemente, que essas ações devem sair dos muros da escola, possibilitando a construção de uma sociedade humanitária.

Diferentes áreas de estudo podem contribuir com a formação de um ser sensível, mas esse artigo destaca o potencial do trabalho com o teatro e com a performance, por seu aspecto, necessariamente, coletivo e completamente dialógico. E quando pensamos em formar seres sensíveis, precisamos discutir e pensar que teatro e performance precisam, de alguma maneira, adentrar a Educação Infantil, uma das fases mais importantes para se desenvolver o sensível.

Os jogos, experimentações, práticas corporais e lúdicas na Educação Infantil aguçam as crianças a desenvolverem suas percepções sobre o outro e sobre si mesmo; dão a possibilidade de experimentarem situações e emoções diferentes, compartilhando experiências e vivências; instigamnas a intuírem sobre suas próprias práticas, ao mesmo tempo em que oportunizam aos estudantes 
perceberem as sensações e sentidos de diferentes atividades que implicam a criação coletiva, e desenvolvem o saber ouvir, o ver, o falar, o respeitar e compreender o outro e a si mesmo.

Ao pensar a intuição, a percepção, a emoção, a criação e a sensibilidade, a partir do teatro e da performance, como um dos caminhos para a educação sensível, esse estudo contribui para ampliação do conhecimento no que se refere aos aspectos constitutivos de uma formação de seres humanos mais altruístas em uma sociedade que tende, cada vez mais, ao individualismo.

Se desejamos uma sociedade e, por consequência uma educação mais humana, uma das possibilidades atuais para se chegar à isso é a educação pela via do sensível, com professores e educandos sensíveis ao outro. Qualquer sistema educacional que ignore isso corre o risco de limitarse no que se refere ao aprendizado humano e à importância da experiência e do afeto quando se fala de educação; quando se fala de uma educação sensível.

\section{REFERÊNCIAS}

ARENHARDT, S. et al. A formação do professor para uma educação do sensível na multiculturalidade. Canfluencias. Santa Maria-RS: Facos-UFSM, 2006. Disponível em: < http://coral.ufsm.br/gpforma/2senafe/PDF/025e3.pdf>. Acesso em: 07 janeiro 2017.

BAKHTIN, M. M. O discurso na poesia e o discurso no romance. [1934-1935]. In: Questões de literatura e de estética: a teoria do romance. Trad. do russo Aurora Fornoni Bernadini et al.. 4. ed. São Paulo: Editora Unesp, 1998.

BAKHTIN, M. M. Metodologia das ciências humanas. [1959-61/1979]. In: . Estética e criação verbal. Trad. Paulo Bezerra. 4. ed. São Paulo: Martins Fontes, 2003.

BRAIT, B.; MELO, R. Enunciado/enunciado concreto/enunciação. In: BRAIT (Org.). Bakhtin: conceitos-chave. 5. ed., $3^{\mathrm{a}}$ reimpressão. São Paulo: Contexto, 2016. p. 61-78.

BRAIT, B. A Personagem. São Paulo: Contexto, 2017.

CANIATO, Angela Maria Pires; NASCIMENTO, Merly Luane Vargas. A subjetividade na sociedade de consumo: do sofrimento narcísico em tempos de excesso e privação. Arq. bras. psicol., Rio de Janeiro, v. 62, n. 2, p. 25-37, 2010 . Disponível em <http://pepsic.bvsalud.org/scielo.php?script=sci_arttext\&pid=S1809$52672010000200004 \& \operatorname{lng}=$ pt\&nrm=iso $>$. acesso em 24 maio 2017.

CASTANHEIRA, L. Teatro ou performance? Quando os discursos atravessam os procedimentos. In: Rascunhos, V. 4. N.1. UFU: Uberlândia, 2017. Disponível em: <http://www.seer.ufu.br/index.php/rascunhos/article/view/36123> Acesso em: 25 de maio de 2017.

FIORIN, J. L. Introdução ao pensamento de Bakhtin. 2. Ed. São Paulo: Contexto, 2016.

GONÇALVES, J. C. O pensamento bakhtiniano: diálogos com a pesquisa em educação. In: AGUIAR, N.; RAUSCH, R. Pesquisa em educação: pressupostos epistemológicos e perspectivas de investigação. Blumenau: EdiFURB, 2011. pp. $167-182$.

GONÇALVES, J. C. Das relações [amorosas e sedutoras] entre Educação, Linguagem e Teatro: reflexões bakhtinianas. In: HAGEMEYER, R. C.; SÁ, R. A.; GABARDO, C. V. (Orgs.). Diálogos epistemológicos e culturais. Curitiba: W\&A Editores, 2016. p. 217-232.

LARROSA, J. Notas sobre a experiência e o saber da experiência. Revista Brasileira de Educação, nº 19, p.20-28, 2002. Disponível em: < http://www.scielo.br/pdf/rbedu/n19/n19a02.pdf>. Acesso em: 09 de janeiro 2017. 
OLIVEIRA, P. Graus de interação no espaço físico e virtual. In: SOTO, U.; MAYRINK., M.F; GREGOLIN, F. Linguagem, Educação e Virtualidade. São Paulo: Editora UNESP, 2009.

OSTETTO, L. E. Entre a prosa e a poesia: fazeres, saberes e conhecimento na educação infantil. In: PILLOTTO, S. S. D. (Org.). Linguagens da arte na infância. Joinville, SC: UNIVILLE, 2007. p. 29-45.

PEREIRA, A. C. C. A dança na educação infantil - desafios e possibilidades: projeto linguagem corporal na educação infantil na rede municipal de educação de Belo Horizonte. In: MUNIZ, M. L.; CRUVINEL, T. B. (Orgs.). Pedagogia das artes cênicas: criança, jogo e formação. Curitiba: CRV, 2016. p. 33-44.

PILLAR, A. D. A educação do olhar no ensino da arte. In: BARBOSA, A. M. (Org.). Inquietações e mudanças no ensino da arte. 5. ed. São Paulo: Cortez, 2008. p. 71-84.

PILLOTTO, S. S. D. Educação pelo sensível. Linguagens - Revista de Letras, Artes e Comunicação ISSN 1981 - 9943 , Blumenau, v. 1, n. 2, p. 113-127, mai./ago. 2007a. Disponível em: <http://proxy.furb.br/ojs/index.php/linguagens/article/view/683/599>. Acesso em: 26 jan. 2017.

PILLOTTO, S. S. D. As linguagens da arte no contexto da educação infantil. In: (Org.). Linguagens da arte na infância. Joinville, SC: UNIVILLE, 2007b. p. 17-28.

SCHECHNER, R; ICLE, G; PEREIRA, M de A. O que pode a performance na educação? Uma entrevista com Richard Schechner. Educação e Realidade. Santa Maria: v. 35, n. 2, p 23-35, 2010. Disponível em <http://seer.ufrgs.br/index.php/educacaoerealidade/article/view/13502/7644> Acesso em 10 mai 2017.

SCHECHNER, R. 2006. “O que é performance?” In: performance studies: an introduccion, second edition. New York \& London: $\quad$ Routledge, $\quad$ p.28-51 Disponível em <http://www.performancesculturais.emac.ufg.br/up/378/o/O_QUE_EH_PERF_SCHECHNER.pdf> Acesso em 12 mai 2017.

.O que é performance? O Percevejo, Rio de Janeiro, ano 11, n.12, p.26-50, 2003.

TAYLOR, D. O arquivo e o repertório: Performance e memória cultural nas Américas. Belo Horizonte: Editora UFMG, 2013.

SLADE, P. O jogo dramático infantil. São Paulo. Summus Editorial, 1978.

VANI, A. C. A educação do sensível: saberes educativos que circulam na compreensão do ser humano. Unoesc \& ciência - ACHS, Joaçaba, v. 4, n. 1, p. 7-18, jan./jun. 2013. Disponível em: <http://editora.unoesc.edu.br/index.php/achs/article/viewFile/2691/pdf〉. Acesso em: 26 jan. 2017. 


\section{TEATRO E PERFORMANCE NA EDUCAÇÃO INFANTIL: [COR]POSSIBILIDADES PARA UMA EDUCAÇÃO SENSÍVEL}

RESUMO

Trata-se de um estudo teórico que tem por objetivo refletir sobre questões relacionadas à educação sensível, tomando o teatro e a performance na Educação Infantil como áreas que podem contribuir para o desenvolvimento sensível do estudante. Num primeiro momento situa-se o contexto da investigação e em seguida discutem-se as bases que formam a proposta de uma educação sensível. Logo após aborda-se o teatro e a performance na Educação Infantil como [cor]possibilidades para se chegar a uma educação sensível, e por fim conclui-se que uma educação que não leva em consideração o racional e o sensível para a formação humana tem grande chance de ser limitada, incompleta e desconectada das necessidades atuais da pesquisa em educação.

Palavras-chave: Educação Sensível; Teatro e Performance; Educação Infantil.

\section{THEATER AND PERFORMANCE IN EARLY CHILDHOOD EDUCATION: [BODY]POSSIBILITIES FOR A SENSITIVE EDUCATION}

ABSTRACT

It is a theoretical study that have for objective to approach subjects related to the sensitive education, being the theater and performance in early childhood education areas that can contribute to the sensitive development in the student. In the first stage the context of the investigation is situated, and then the bases that constitute the proposal of a sensible education are discussed. Soon after, the theater and the performance in the early childhood education as one of the [body]possibilities to arrive to the that sensitive education, and finally it is ended that an educacion tha doens't take into account the rational and the sensitive, united, for the human formation, has great chance of being limited, incomplete and disconnected of the research in education.

Key words: Sensitive Education; Theater and Performance; Early childhood education.

\section{TEATRO Y PERFORMANCE EN LA EDUCACIÓN INFANTIL: [COR]POSIBILIDADES PARA UNA EDUCACIÓN SENSIBLE}

RESUMEN:

Se trata de un estudio teórico que tiene por objetivo reflexionar sobre cuestiones relacionadas con la educación sensible, tomando el teatro y la performance en la Educación Infantil como áreas que pueden contribuir al desarrollo sensible del estudiante. En un primer momento se sitúa el contexto de la investigación y luego se discuten las bases que forman la propuesta de una educación sensible. Luego se aborda el teatro y la performance en la Educación Infantil como [color] posibilidades para llegar a una educación sensible, y por fin se concluye que una educación que no tiene en cuenta lo racional y lo sensible para la formación humana tiene Gran posibilidad de ser limitada, incompleta y desconectada de las necesidades actuales de la investigación en educación.

Palabras clave: Educación sensible; Teatro y Performance; Educación Infantil. 